\title{
The Evolution of Rationality and Modernity Crisis
}

\author{
Chenggang Zhang \\ School of Social Sciences, Tsinghua University, Beijing, China \\ Email: zcgice@tsinghua.edu.cn
}

Received January $10^{\text {th }}$, 2013; revised February 21 $1^{\text {st }}, 2013$; accepted March $1^{\text {st }}, 2013$

Copyright (C) 2013 Chenggang Zhang. This is an open access article distributed under the Creative Commons Attribution License, which permits unrestricted use, distribution, and reproduction in any medium, provided the original work is properly cited.

\begin{abstract}
As the necessary result of the modernity movement, the technological problems not only reflect the conflict between technology and nature, but also reveal the inherent contradiction of the modernity culture. This study aims at providing a new explanation of modernity crisis partly caused by technology from the perspective of the evolution of rationality. As one of the core cultural ideas of modernity, rationality is both the source and the driving force of modernity. There does not exist absolutely pure rationality, and what really exists can only be a social and historical rationality situated in certain context. This paper identified three types of rationality in the movement of modernity: enlightenment rationality, science rationality, and technological rationality. The author considers that the transformation from Enlightenment rationality to technological rationality and the domination of technological rationality in modern society will answer for the emergence of technological problems partially.
\end{abstract}

Keywords: Technology; Risk; Rationality; Modernity Crisis

\section{Introduction}

Since the Industrial Revolution, sustained technological development has been proving the myth of man's domination of nature and the optimism of the age of Enlightenment. In the twentieth century which has achieved great success, and which has brought about enormous material prosperity, it becomes more and more impossible to ignore the problems laid bare in modern technology. At the present age, many crises human beings are facing, such as ecological, civilization, moral and value crisis, etc, can find their pathological roots in technology. Just as Loon states, until relatively recently, most risks have been allies to technology (Van Loon, 2003: p. 56).

Modern technology is not an isolated material system, which is intertwined with such factors as civilization, mentality, institutions, and nation, etc.; the development of modern technology is far from an isolated action, the ideological and cultural context behind which plays an important supporting role, and it is just this kind of invisible "other things" that sustain technology and determine the direction of its development. How technology dialogizes with nature, depends not on technology itself, but on the view of nature, on the special cultural ideas. The culture of knowledge and technology exists before knowledge and technology, and this culture determine the way of revealing realistic problems and posing problems through technology. (Koslowski, 1999).

In The Turning Point, Capra (1982) had shown us how the revolution in modern physics foreshadows a similar revolution in many other sciences and a corresponding transformation of world views and values in society. Modern technology originated from the modernity culture, so confronting with technological problem, we should rethink the culture and value behind technology.

As a tradition with sediments accumulated over so many years, rationality originates in ancient Greece (Buxton, 1999). Although the ancient Greeks make certain progress in applying rational experience, and their main achievements manifested in their rational mythic thinking, as Barber states: what the Greeks are more interested in is the inner consistency within a system, but not the objective experience, and Greek thought does not show consistent concern for the test of its generalized propositions in their experience (Barber, 1991). In the Middle Ages, the Greek speculative reason serves as a tool to demonstrate the legality of religion. Because of religion's tolerance for rationality, it becomes the core of contemporary cultural values in the form of religion, becomes the guideline to direct people's thoughts and actions, which made the qualitative conservation and continuation of the ancient Greek thought possible (Grant, 2001).

Such events as the discovery of the "New World", Renaissance, and the Reformation, etc, which took place before and after 1500 DC form the dividing line between modern time and the Middle Ages, and modernity is the break of western thought, just as Capra (1984: p. 40) states: “Man's view of world and their way of thinking underwent dramatic changes, new spirits and new views of cosmos brought about by which shaped the image of western civilization which serves as the characteristic of modern society, and became the basis of the idea model which has been dominating over the past 300 years." Modernity expects to pursue perfection and freedom of central subjectivity in its belief in rationality and progress. Those cultural ideas co-exist with it include: rationality, subjectivity, progress, freedom, etc. The emergence of technological problems is inseparable from those deep-seated cultural ideas underlying modernity movement. When questioning the contributing factors of technological problems, the world view and value system which exist on the basis of our modern culture should be 
tested again (Avgerou \& McGrath, 2007).

\section{The Conception of Rationality in the Context of "Enlightenment Movement"}

The word "enlightenment" originally means making clear, clarification, illumination, and giving more knowledge, information and inspiration to somebody, and "Enlightenment Movement" means the liberation movement of thought and society (Horkheimer \& Adormo, 1972: p. 3). It castigates foolishness and ignorance, negates ecclesiastical power, royal right, and privilege with equality and freedom, and its ultimate aim is to free man from theological domination, and ultimately establish man's position of as a subjectivity.

During the process of promoting humanity, Enlightenment Movement tries its best to extol the rational spirit of demonstration and analysis, and finally establishes the high position of rationality. As Marcuse states: "All that contradict rationality or that are unreasonable are thought to be something that must be done away with. Rationality is constructed as a court which makes judgments for anything" (Marcuse, 1989: p. 176). In the enlightenment project, rationality becomes the motive force and source of all kinds of progress, and scientific domination of nature permits freedom from shortage and the violence of natural calamity; the reasonable form of social organization and the development of rational model of thought permit the liberation from myth, religion and superstition. People believe that under the guidance of rationality, they can free themselves from various natural and historical fetters, determine historical direction and aim relying on their own power, and shape their world and life freely (Honneth, 1987).

In the period of "enlightenment movement", rationality permeates through the works, speeches, deeds, and actions of those enlightenment thinkers, who also extend rationality from logical and epistemological fields to political field, making it a weapon for the bourgeoisie to criticize unreasonable systems, to oppose feudalism and religion. With its spiritual pursuit of criticism and negativity, enlightenment rationality impels the course of the Renaissance, the religious reformation, the science revolution and the bourgeois revolution. The age of Renaissance is an age when the decline of religious theology, the establishment of scientific thought, the seeking of reasonable society, and the discovery of man take place; the Reformation plays a progressive role in opposing Catholic tradition; the scientific revolution in modern times declares the split of natural science and theology; the bourgeois revolutionary movement leads to social transformation, social form transformed from feudal society which integrates church and state and is based on agriculture to capitalist society which separates church and state and is based on industry (Goody, 1993).

During the enlightenment movement period, rationality was a unified whole originally, when applied to different cultural fields, it assumed different forms. For instance, Kant once categorized rationality into theoretical rationality, practical rationality and aesthetic judgment, and constructed modern knowledge on corresponding bases (Friedman, 2002). Later, Weber put forward the conception of "reasonability"1, holding that rationality could have dramatically different meanings, and dividing

${ }^{1}$ Rationality has been recognized as perhaps the major theme in Max Weber's oeuvre. Acturally Stephen Kalberg identified four types of rationality in Weber's literatures: practical, theoretical, substantive, and formal. it into instrument reasonability and value reasonability. Actions with instrument reasonability is based on the estimation of the instrument which can be used to achieve the end and the achievement of the end is conditional on calculation and prediction of the consequences, and in essence, it is concerned with means and end, with the applicability of those means which are more or less taken for granted, but not with whether the end itself is reasonable or not. Value reasonability bases itself on the reasonability of faith and ideal, and this kind of ideal and faith meet value criterion, so people can accomplish their actions regardless of conditions and costs, and regardless of consequences (Kalberg \& Stephen, 1980).

Historically, Whether Kant's theoretical rationality, practical rationality and aesthetic judgment, or Webber's instrument rationality and value rationality, they are all subordinate to the category of enlightenment rationality, play different roles in different fields, and are irreplaceable. However, with the development of natural science and the rising of industrial revolution, the unified whole of enlightenment rationality breaks up structurally and loses balance, with instrument rationality evolving gradually into dominant rationality (Hindess, 1987).

\section{The Conception of Rationality in the Context of "Scientific Revolution"}

Since the Enlightenment, rationality and technology become two main forces which impel the modernity movement. "Western civilization benefits enormously from the new force of rational thinking produced by the ancient Greek society and new technology" (Barber, 1991: p. 47). The changes of rational spirit are closely linked with the course of scientific revolution. Western society and its ancestor undergo continuous progress in rational empirical thinking and the control of nature. Every age makes its contribution to the flow of development, and the development in modern times is the formation of new knowledge and its new application. (Barber, 1991: p. 56)

Improving people's life and enhancing social welfare are important objectives of the Enlightenment Movement. Scientific technology helps develop man's power of understanding, helps man acquire rationality, and helps man's liberation, and also has practical values in many industries. Also, with the establishment of enlightenment rationality, scientific technology makes rapidest progress. At the same time, with the proceeding of scientific revolution that started from Copernicus' "heliocentric theory", enlightenment rationality combines closely with the context of the times, and new blood is continuously instilled into it, so it acquires new contents, and forms scientific rationality with the mathematicalization of nature as its model (Zhang, 2005: pp. 125-126).

Just as Barber put it, "The importance of the changes within rational thinking and empirical science between the sixteenth and seventeenth century lies in clarifying the merits of combining rational thinking and direct observation of the empirical world" (Barber, 1991: p. 61). As the "father of modern science", Galileo accomplishes epoch-making achievements which manifeste not only in his laying foundation for classic mechanics, but more importantly, in his originating mathematical experimental methods, in his establishing the basic framework of the whole methodology of natural sciences and in his creating a new model of scientific rationality.

It is the common faith of those scientific masters to pursue mathematical harmony, but different from Copernicus and Ke- 
pler, Galileo no longer concerns himself with such supernatural things as "celestial music", "mythic reasons", etc., and what he goes for are realistic mathematical relationships and eternal natural law which exist in nature. When questioning closely the numerous and complicated natural things mathematically, Galileo also changes Aristotle's way to ask questions. In his mind, people put their energy into questioning closely such Aristotelian concepts as end, form, nature, and natural position, etc, to no avail. He admits that he knows nothing of natural end, ultimate cause, and it is better to say "I don't know" than to declare and exaggerate. Therefore, in the problem of the falling body, what Galileo questions is no longer the ultimate cause for the action, but the mathematical law it goes by. During the course of seeking certain scientific knowledge, he successfully creates the scientific method that combines mathematics and experiment. According to him, this method is much more conducive to human beings than Aristotle's method of seeking final cause, because only the knowledge acquired by means of positivistic method is certain knowledge which is truly useful. He confines the object of study within the limits of primary qualities which can be quantified, maintaining that only those primary qualities which conform to mathematical necessity are things' true qualities which exist objectively (Pitt, 1988).

In fact, Galileo's scientific model is a certain kind of "project” of nature according to humanistic spirit with social and historical practice carried out at that time as the starting point. He maintains that secondary qualities should be reduced to primary qualities, that substance should be quantified and abstractized, and that thinking universality, precision and positivity and determinism of knowledge should be sought after within the framework of pure mathematics. The core of his idea is the mathematicalization of nature (Hadden, 1994).

As a representative of rationalism, Descartes makes great contribution to liberating philosophical thought from the bondage of traditional scholasticism. He aims to develop mathematical deduction, making the rationality in the studies of natural science more purified, and more abstractized. Descartes excludes the empirical elements Galileo preserved for natural science from the premise of mathematical deduction, pursues more complete rationality, and confers greater power on rationality. He holds that observations and experiments can only be used to explain those deductions that are deduced from directly given conceptions, but cannot serve as the starting point of mathematical deduction. He maintains that the content of ideological experience should be eliminated, and that the pure form of thinking should be considered as the most reliable standpoint. He faithfully believes in the possibility of constructing objective knowledge of the world of "substance" through mathematical methods on the basis of rationality, thinking that pure rationality itself can provide absolutely reliable concepts and methods for scientific knowledge (Williams, 2005).

Undoubtedly, Galileo, Descartes, etc., have made outstanding contributions to the combination of original enlightenment rationality and the context of the age, and in the spreading of modernity movement all over the western world they have played a very important role. Under their manipulation, a rationalized world begins to come into being.

However, Galileo would necessarily discard other qualities possessed by natural objects except quantitative qualities when pursuing abstract scientific knowledge through mathematicalization of nature. These other qualities include various perceptual qualitative qualities, and other qualities which have ethical and aesthetical implications and which are related to human's history. The formation and development of this model foreshadows later interfluve of rationality. The inquiry into certainty, positivity, and universality is necessarily related to the demand for the practicality, utilitarianity of scientific knowledge, "since the hidden structures and law of repetition of all things can be grasped accurately, then in principle, it is possible to design an operative aim according to this grasp and then to reproduce it or produce it by means of technology” (Zhang, 1995: p. 101). Thus, rationality itself is inevitably given an instrumentalistic property.

As a matter of fact, there does not exist what Descartes calls absolutely pure rationality, and what really exists can only be a social and historical rationality situated in certain context. It is just because of the social and historical characteristics of rationality that it possesses the possibility to be integrated into different levels and different sides of social structure, and that it can fulfill various social functions, can combine scientific technology, the carrier of rationality, with specific historical subject, social life, ideology, and "purport" and "tradition" which dominate, etc, and make it function as an internal cause; and these characteristics can also make it possible for rationality to change and adjust its structure and function, and through a series of technological revolutions, to evolve into technological rationality which is shaped by "life world" and is used to design this “life world”(Gigerenzer, 1996; MacIntyre, 1988).

\section{Industrial Revolution and the Domination of Technological Rationality in Modern Society}

In modernity movement, in order to acquire reliable scientific and technological knowledge that can conquer nature, enlightenment rationality will necessarily demand to reduce objects to certain universal quantities, to view nature as quantified world that can be learned mathematically, and to abstractize natural knowledge to quantitative mathematicalized system.As Marcuse put it: "to enlightenment, anything that does not go by computing and utilitarian rules is doubtable" (Marcuse, 1989: p. 179). During the course of seeking scientific knowledge, enlightenment rationality gradually evolves into a kind of "thinking machine" or "instrument rationality" with abstract universality and repeatability. And its inherent social, historical, mankind's and cultural meanings have potential dangers of being destructed. With the coming of industrial revolution, vigorous practice activities of industrial technology transform this possibility into reality. With the proceeding of modernity movement, rationality degenerates into a suppressing force and dominating method gradually, and enlightenment rationality degenerates into technological rationality and gradually occupying the core position of social culture (Horkheimer \& Adormo, 1972).

In impelling the course of western modernity movement, Industrial Revolution plays a very important role, and just because of this, the academic values it possesses have received widespread attention, and many different interpretations from different points of view co-exist with one another. For example, Cipolla explain Industrial Revolution from the perspective of the energy using. He states that the Industrial Revolution "can be defined as the process by which a society acquired control over vast sources of inanimate energy" (Cipolla, 1976: p. 274). Norbert Winer also considered the replacement of human muscle as a source of energy to be the only "industrial revolution" 
(Weiner, 1950). Bauman, famous for his studies of modernity and post-modernity, provides another point of view, maintaining that "the liberation of means from ends lies at the heart of modern revolution" (Bauman, 1993: p. 190). And Ellul move forward a great step: "Technology is defined by the "complete separation of the goal from the mechanism, the limitation of the problem to the means, ..."” (Ellul, 1964)

It is not difficult to see that it is just in Industrial Revolution that the priority of instrument over end is established." Efficiency, precision, objectivity" is exaggerated infinitely, and the world is placed under the control of instrument rationality, and the rich meanings of life world have diminished. Technological rationality that has grown up in modernity movement gradually occupies the core position of western culture, intrudes into every side of contemporary social structure, and dominates every field of modern social life. According to Bauman, we live in a technological world nowdays, which is a disenchanted world: a world without meaning of its own (Bauman, 1993: pp. 188-193).

In Technopoly, Postman describes the development and characteristics of a "technopoly": the domonation of technological rationality. He states that in modern society "the culture seeks its authorisation in technology, finds its satisfactions in technology, and takes its orders from technology". The technopoly is characterised by a surplus of information generated by technology, which technological tools are in turn employed to cope with, in order to provide direction and purpose for society and individuals (Postman, 1993: pp. 71-72).

Nowdays Rationality is a social rationality which has both a technical and normative dimension. Feenberg summarize three principles to resemble our ideas about rationality in modern society: 1) exchange of equivalents, 2) classification and application of rules, 3) optimization of effort and calculation of results. Rationality is not necessarily good or even successful, he points out: Hitler's Germany exhibited a high degree of organizatioal rationality with consequesnces both evil and disastrous (Feenberg, 2008).

\section{Technology Rationality and Modernity Crisis}

The conception of rationality is closely related to the development of modernity movement. Modernity is the historical condition that characterizes modern societies, and theories of modernity aim to describe and analyze this historical condition (Misa, Brey, \& Feenberg, 2004). Nowadays the modernity studies is a very important academic field both in China and beyound, and the interpretations and criticisms of modernity, in general, go beyond semantic category, possessing very complicated philosophical, cultural and sociological implications. The different attitudes towards "modernity" even form completely different thought and knowledge scene (Calinescu, 1987; Therborn, 1995; Wittrock, 2000). Modernity first can be understood as a historical concept in periodic historical sense, which is used to describe the historical changes and developments and the basic characteristics of western society since Renaissance. As Heidegger say "the fact that whatever is comes into being in and through representedness transforms the age in which this occurs into a new age in contrast with the preceding one" (Hedegger, 1977: p. 130). Modernity is not merely a temporal category, but represents new thoughts and ideas which underlie historical changes dominating the philosophical, economic and cultural fields in modern society.

Modernity movement is a movement that strongly challenges modern civilization. "In these several hundred years, man has undergone complete and dramatic changes, with which all those changes in previous historical periods cannot be compared, and each pre-modern nation is still running more quickly into it. These 'inside' nations cannot see the prospect of going out of this specific historical period” (Bao \& Stackhouse, 2000: p. 29). The modern discourse starts when philosophers clearly realize that the problems man are facing in a new age cannot appeal to the forces beyond man's rationality, cannot rely on traditional myths and religion, cannot appeal to traditional metaphysics, but should construct code of ethics based on rationality. They declare that the void left by the now extinct or ineffective moral supervision of the Church can and ought to be filled with carefully and artfully harmonized set of rational rules (Baumman, 1998: p. 6). The basic characteristic of modernist world view is rationalism, rationality is the key word of modernity movement.

Western modernist culture with rationalism embedded in it is founded on the priority of technological knowledge over other cultural values. Modern technology is regarded as the basis of the progress of rationalism, and people who get involved in modernity movement believe that technological progress can lead to moral improvement. Civilization and progress manifest in knowledge accumulation and technological progress, and modernity means the potentials of the reasonability of cognition of theoretical knowledge is transformed into the reasonability of economic system and administrative system (Hennen, 1999).

As an important word produced by enlightenment movement, "rationality" is limited with the narrow category of technological rationality in its historical evolvement. In modern society, the dimension of technological rationality and its concrete forms such as system, scientific technology, and market expand uncontrollably, which makes rationalized society increasingly take on an extremized tendency, thus leading to the rebel against enlightenment itself. Modernity and industrial technology system that it sustains bring human beings to dash to the peak of material wealth, which seems to present a bright prospect before them. However, in the late modern age after the twentieth century, instrument control system is laid much barer than before, and its negative consequences are more evident, and many forms of counteraction appear. Modernity receives reflection and criticism from more and more scholars (Giddens, 1991; Zimmerman, 1990).

It is not difficult to see that as mathematicalized, abstractized and positivized treatment of nature, as scientific "design" related with specific social history, cultural tradition and way of daily life, technological rationality has deviated completely from humanism advocated by enlightenments rationality to fight for man's freedom and liberation. It expands but at the same time, devours man's freedom, with hidden inherent conflicts that cannot be solved by itself. Technological rationality extols the principle of materialization, maximize the benefits, turns man into objects, instruments and machines; make them forsake their aims and pursuit of value, becoming rootless, characterless and meaningless man. Just as Louis Dumont points out profoundly, "there is no humanly significant world...This world devoid of values, to which values are superadded by human choice, is a subhuman world, a world of objects, of things..." (Dumont, 1986).

As a liberating force, Enlightenment rationality has played an important role in liberating mankind from feudal rule, especially from God's rule, however, with the proceeding of the course of modernity, rationality begins to go to its opposite, 
evolving into means to achieve utilitarian ends, becoming instruments to rule and enslave man. Technological rationality finally grows into a suppressing force, a ruling means, just as Adorno and Horkheimer point out: there exists certain complicit relationship between enlightenment and myth. "Myth is already enlightenment, and enlightenment in turn becomes myth" (Adorno \& Horkheimer, 1997). In "technological society" where technological rationality prevails, science and technology is alienated into a new form of control used to replace traditional political rule by late capitalist society, becomes a new ideology that has unpoliticized demand, and shapes a onedimensional society and one-dimensional man with irresistible forces in a more hidden manner (Marcuse, 1964).

In short, in modernity movement, a whole set of guiding conceptions, such as mathematicalization of nature, the priority of means over end, conquer and control of nature, etc, on which the emergence and development of modern technology relies, are formed. According to these conceptions, people pay much attention to the utilitarianity of technology, to the possibility of knowing and controlling nature by means of such rational methods as logical deduction and mathematical analysis. This is the so-called "technological rationality". Weber's rationalization theory explains the rise of "calculation and control" in modern societies (Weber, 1958). Under the control of the ideas of technological rationality, modern technology emerges and develops. New "technological paradigm" shows the combination of knowledge and material. In such fields as science, war, and navigation, technological discoveries of printing, gunpowder, and compass can "help us think over those secrets which have been locked up in the depths of nature", and "unlike those old technology which guides natural process in a gentle manner, it uses forces to possess and conquer it, until it shakes its whole foundation" (Merchant, 1990).

Henceforth, it is possible for people to use entirely new knowledge and comparatively mature technological means to know and transform nature again. The breaking out of Industrial Revolution and its spread and development in EuroAmerica makes it possible for mankind's dream of conquering nature which has slept in spiritual world for several thousand years to come true. By means of technology, man's power becomes increasingly greater, and finally man appears as the master of nature on the earth. However, the ruthless massacre of nature will inevitably result in the appearance of a series of technological problems (Beniger, 1986).

Modernity movement creates technological rationality, which dominates in "technological society" and determines such cultural ideas as conquer and measurability of nature, priority of thinking efficiency, predetermination of material demands, and bureaucratization of society. Technological rationality develops or sublates the ancient Greek mathematical rationalism, however, the dimension of efficiency and material orientation emphasized by it is bound to neglect man's spiritual meanings and values, which in fact deviates from the original meaning of enlightenment rationality, and then becomes harmful to modernity itself. If technological rationality becomes hegemonic rationality in a society and expands to all fields, this society must have potential crises. (Alario \& Freudenburg, 2003) Undoubtedly, it will be helpful to correctly understand rationality and rectify the long-standing mistaken ideas of rationality to interpret the outer cultural context of the contributing factors of technological problems from the point of view of the evolution of rationality.

\section{Conclusion and Discussions}

This study focus on providing a new explanation of the modernity crisis caused by technology from the point of view of the evolution of rationality. This paper identified three types of rationality in the movement of modernity: enlightenment rationality, science rationality, and technological rationality. The author considers that the transformation from the Enlightenment rationality to the technological rationality and the domination of technological rationality will answer for the emergence of technological problems partially. I would like to summarize it as follows.

Firstly, the development of modern technology is far from an isolated action, the ideological and cultural context behind which plays an important supporting role and it is just this kind of invisible "other things" that sustain technology and determine the direction of its development. As the necessary result of the modernity movement, the technological problems not only reflect the conflict between technology and nature, but also reveal the inherent contradiction of the modernity culture. It will be helpful to correctly understand rationality and rectify the long-standing mistaken ideas of rationality to interpret the outer cultural context of the contributing factors of technological problems.

Secondly, rationality originates from ancient Greece. In the transformation process from traditional society to modern society, thinkers of the Enlightenment highly value the rational spirit of positivism and analysis, and the authority status of rationality is further confirmed in the period of scientific revolution. Rationality is one of the core cultural ideas of modernity. Absolutely pure rationality does not exist, and what really exists can only be a social and historical rationality situated in certain context.

Thirdly, with the development of history, the rationality combine with industrial revolution and modernity, evolved into a technological one, which possess lofty status in modern society. Rationality is both the source and the driving force of modernity The Enlightenment rationality used to be a unified whole, and can be applied to different fields with different manifestations. The rationality is limited to the narrow scope of technical rationality in the process of its evolution. The expansion of technological rationality finally makes it a sort of oppressive forces which lead to the crisis and risk of modernity.

Lastly, the rationality in the context of modernity has both a technical and a normative dimension and it will change its form with the development of history .Technology has spilled over into most aspect of social life, and diverse interest contend for influence over the construction of technological rationality. The author considers that the research approach of the "co-construction" of technology and modernity will provide us with more insights in the future.

\section{Acknowledgements}

Some of the research discussed here received support from the Education Ministry Foundation (Award \#12YJA720032) and Independent Research Projects of Tsinghua University (Award \# 20111080990).

\section{REFERENCES}

Adorno, T. W., \& Horkheimer, M. (1997). Dialectic of enlightenment (2nd ed.). London, New York: Verso Books. 
Alario, M., \& Freudenburg, W. (2003). The paradoxes of modernity: Scientific advances, environmental problems, and risks to the social fabric? Sociological Forum, 18, 193-214.

Avgerou, C., \& McGrath, K. (2007). Power, rationality, and the art of living through socio-technical change. MIS quarterly, 31, 293-315.

Bao, L. M., Stackhouse, M. (2000). A dialectical study on the value of modernity (p. 29). Shanghai: Xuelin Press.

Bauman, Z. (1993). Postmodern ethics (Vol. 195). Oxford: Blackwell Oxford.

Beniger, J. R. (1986). The control revolution: Technological and economic origins of the information society. Cambridge, MA: Harvard University Press.

Buxton, R. G. A. (1999). From myth to reason? Studies in the development of Greek thought. Oxford: Oxford University Press.

Calinescu, M. (1987). Five faces of modernity: Modernism, avantgarde, decadence, kitsch, postmodernism. Durham, NC: Duke University Press Books.

Dumont, L. (1986) Essays on individualism: Modern ideology in anthropological perspective (p. 262). Chicago, IL: University of Chicago Press.

Ellul, J. (1964). The technological society (J. Wilkinson, Trans., pp. 133-143). New York: Random House.

Friedman, M. (2002). Kant, Kuhn, and the rationality of science. Philosophy of Science, 69, 171-190. doi:10.1086/341048

Feenberg, A. (2008). From the critical theory of technology to the rational critique of rationality. Social Epistemology, 22, 5-28.

Giddens, A. (1991). Modernity and self-identity: Self and society in the late modern age. Palo Alto, CA: Stanford University Press.

Gigerenzer, G. (1996). 11 Rationality: Why social context matters. In P. B. Baltes, \& U. M. Staudinger, Interactive minds: Life-span perspectives on the social foundation of cognition (p. 319). Cambridge: Cambridge University Press.

Goody, J. (1993). East and west: Rationality in review. Ethnos, 58, 6-36. doi:10.1080/00141844.1993.9981463

Grant, E. (2001). God and reason in the Middle Ages. Cambridge: Cambridge University Press. doi:10.1017/CBO9780511512155

Hadden, R. W. (1994). On the shoulders of merchants: Exchange and the mathematical conception of nature in early modern Europe. Albany, NY: State University of New York Press.

Heidegger, M. (1977). "The Age of the World Picture" in the question concerning technology and other essays (W. Lovitt, Trans.). New York: Harper and Row.
Hennen, L. (1999). Participatory technology assessment: A response to technical modernity? Science and Public Policy, 26, 303-312. doi:10.3152/147154399781782310

Hindess, B. (1987). Rationality and the characterization of modern society. In S. Lash, \& S. Whimster (Eds.), Max Weber: Rationality and modernity (pp. 137-153). Boston, MA: Unwin Hyman.

Honneth, A. (1987). Enlightenment and rationality. The Journal of Philosophy, 84, 692-699.

Marcuse, H. (1964). One-dimensional man. Boston, MA: Beacon Press. MacIntyre, A. (1988). Whose justice? Which rationality? (p. 421). Notre Dame, IN: University of Notre Dame Press.

Merchant, C. (1999). The death of nature: Women, ecology, and the scientific revolution (p. 189). Changchun: Jilin Publishing House.

Misa, T. J., Brey, P., \& Feenberg, A. (2004). Modernity and technology. Cambridge, MA: MIT Press.

Noppen, P. F. (2012). Reflective rationality and the claim of dialectic of enlightenment. European Journal of Philosophy, Early Review. doi:10.1111/j.1468-0378.2012.00538.x

Pitt, J. C. (1988). Galileo, rationality and explanation. Philosophy of Science, 55, 87-103. doi:10.1086/289418

Postman, N. (1993). Technopoly: The surrender of culture to technology. New York: Knopf.

Therborn, G. (1995). Routes to/through modernity. In M. Featherstone, S. Lash, \& R. Robertson (Eds.), Global modernities (pp. 124-139). London: SAGE Publications Ltd. doi:10.4135/9781446250563.n7

Van Loon, J. (2003). Risk and technological culture: Towards a sociology of virulence (p. 56). London: Routledge.

Weber, M. (1958). The protestant ethic and the spirit of capitalism (T. Parsons, Trans.). New York: Scribners.

Williams, B. (2005). Descartes: The project of pure enquiry. London: Routledge.

Wittrock, B. (2000). Modernity: One, none, or many? European origins and modernity as a global condition. Daedalus, 129, 31-60.

Zhang C. G. (2005) Technology, modernity and the future of human being. Beijing: Tsinghua Press.

Zhang, F. Y. (1995) Technological rationality and the experimental style of modern people. Academic Journal of Nanjing University, 2, 101.

Zimmerman, M. E. (1990). Heidegger's confrontation with modernity: Technology, politics, and art (Vol. 558). Bloomington, IN: Indiana University Press. 